\title{
Perovskite-related Oxynitrides in Photocatalysis
}

\author{
Simone Pokrant ${ }^{\star}$, Alexandra E. Maegli, Gian Luca Chiarello, and Anke Weidenkaff
}

\begin{abstract}
Over the last decades photocatalytic water splitting has become of increasing importance for fundamental and applied research, since the direct conversion of sunlight into chemical energy via the production of $\mathrm{H}_{2}$ has the potential to contribute to the world's energy needs without $\mathrm{CO}_{2}$ generation. One of the unsolved challenges consists of finding a highly efficient photocatalyst that is cheap, environmentally friendly, contains exclusively abundant elements, is (photo)chemically stable and absorbs visible light. Photocatalytic efficiency is closely connected to both structural properties like crystallinity, particle size and surface area and to electronic properties like the band gap and the quantum efficiency. Hence extensive control over a large parameter field is necessary to design a good photocatalyst. A material class where the structure-composition-property relations and the influence of substitution effects are well studied is the perovskite-type family of compounds. The perovskiterelated oxynitrides belong to this very flexible compound family where many of the necessary characteristics for a photocatalyst are already given and some of the intrinsic properties like the band gap can be tuned within the same crystal structure by substitution. In this work we present materials' design concepts to improve the photocatalytic efficiency of a perovskite-type catalyst and describe their effects on the photocatalytic activity.
\end{abstract}

Keywords: Oxynitrides · Perovskites · Photocatalysis · Water splitting

\section{Introduction}

\subsection{Water Splitting}

Since the demonstration of photoelectrochemical water splitting by Fujishima and Honda using $\mathrm{TiO}_{2}$ in $1972,{ }^{[1]}$ the idea to produce environmentally friendly fuel by direct conversion of solar energy into hydrogen has grown increasingly popular. During the past years this trend has become even stronger, especially since the growing awareness about the damaging effects of $\mathrm{CO}_{2}$ emission combined with the knowledge of the limited availability of fossil energy resources like oil or coal triggered an intensive search for alternatives. Shining light on a semiconducting photocatalyst leads to absorption of photons and generation of electron-hole pairs. The generated electrons and holes that escape recombination, eventually diffuse to the surface of the photocatalyst particle and are consumed by the oxidation of $\mathrm{O}^{2-}$ to $\mathrm{O}_{2}$ or the reduction of $\mathrm{H}^{+}$to $\mathrm{H}_{2}$, respectively.

${ }^{\star}$ Correspondence: Dr. S. Pokrant Laboratory for Solid State Chemistry and Catalysis Empa

Überlandstrasse 129

$\mathrm{CH}-8600$ Dübendorf

Tel.: +41587654400

E-mail: simone.pokrant@empa.ch
Hydrogen has the potential to serve as the next generation fuel. ${ }^{[2]}$ For this purpose the implementation of water splitting in a technological solution, if possible on a large scale, is necessary. Several concepts have been proposed: One of them is the use of photocatalytically active particles to produce $\mathrm{H}_{2}$ and $\mathrm{O}_{2}$ (overall water splitting), where the photocatalyst particles are either suspended in a liquid or deposited on a film. ${ }^{[3]}$ In many systems either cocatalysts or two different materials are necessary to achieve overall water splitting. ${ }^{[4]}$ The role of the cocatalyst is to promote charge separation of the electron hole pair by introducing an internal electric field and to lower the activation barrier for the surface redox reactions. Another concept is based on the photoelectrochemical cell (PEC-cell). ${ }^{[5]}$ In the PEC-cell, however, oxidation and reduction take place on physically separated electrodes. In theory both electrodes could be photoelectrodes. Today, solar light is used almost exclusively to produce $\mathrm{O}_{2}$ on the photoanode, while the cathode is a standard electrode for $\mathrm{H}_{2}$ production, since the search for suitable photocathode materials is only beginning. ${ }^{[6]}$ In this set-up a bias can be applied to correct for band gap misalignments at the cost of conversion efficiency.[7] Unfortunately none of the concepts has been developed yet to the point that large-scale demonstrators could be built. The goal is to maximize the efficiency for solar energy conversion taking into account all possible technical solutions.

One of the main blocking points apart from the architecture of the devices is the question which material can be used best as a catalyst. The list of the necessary material properties for a good photocatalyst for $\mathrm{H}_{2}$ and/or $\mathrm{O}_{2}$ production is long: Of course it should be cheap, easy to produce, non-toxic and should not contain scarce elements. To harvest sunlight efficiently, the material should absorb in the wavelength range of visible light, where the sun intensity is highest. Moreover, the quantum efficiency needs to be high, as well as the catalytic activity either for $\mathrm{H}_{2}$ and/or $\mathrm{O}_{2}$ production. The catalytic activity is related to many factors, including a large surface area and good crystallinity of the material. ${ }^{[8]}$ Furthermore, the valence and conduction band energies have to be aligned with respect to the water-splitting half reactions. The conduction band has to be higher (more negative) than the reduction potential of $\mathrm{H}^{+} / \mathrm{H}_{2}(-0.41 \mathrm{~V}$ at $\mathrm{pH} 7)$ and the valence band edge has to be lower (more positive) than the oxidation potential of $\mathrm{O}^{2-} / \mathrm{O}_{2}(+0.81 \mathrm{~V}$ at $\mathrm{pH} 7)$ (see Fig. 1). In order to overcome the overpotentials building up at the solid/liquid interfaces, the ideal semiconductor band gap has to be larger $(\sim 2.1 \mathrm{eV})$ than the water-splitting redox potential of $1.23 \mathrm{eV} .{ }^{[9]}$ In this context, the boundary condition for the PEC cell applications are easier to satisfy, since in this configuration an external bias can compensate for non-matching band positions. ${ }^{[10]}$ Another very important criterion is the long term stability of the catalytic material against corrosion and/or photocorrosion during operation. 


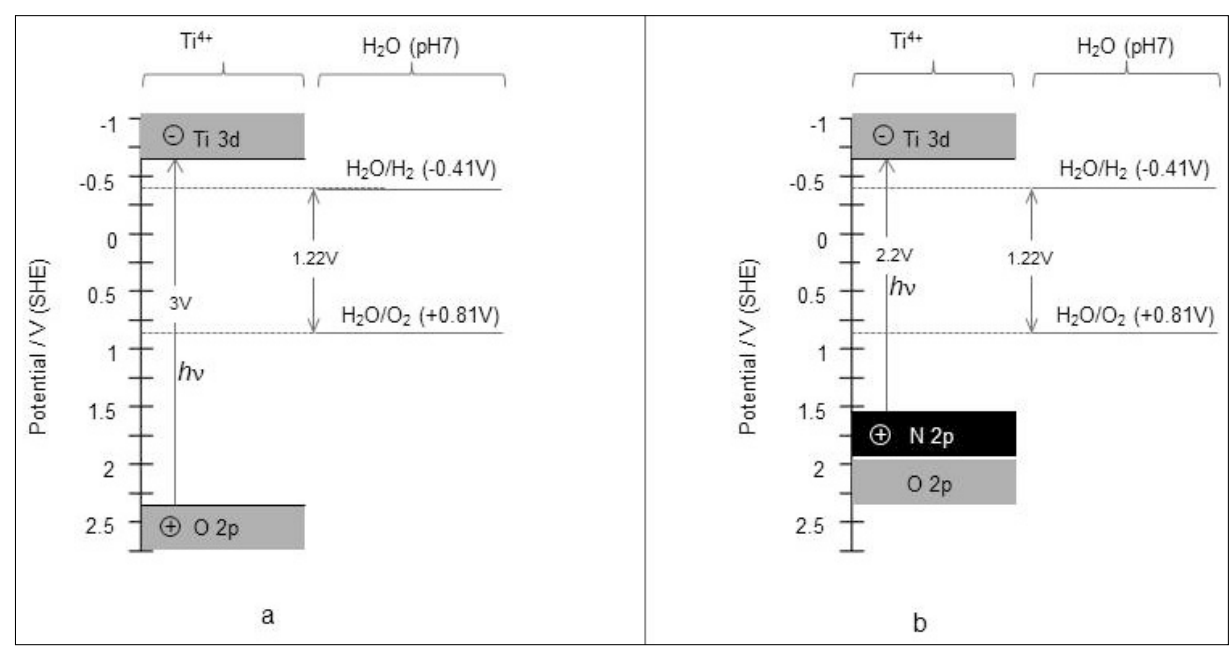

Fig. 1. The energy diagram of a $\mathrm{Ti}^{4+}$ oxide is represented in (a). The modification provoked by $\mathrm{N}$-substitution on the O-site is displayed in (b).

Up to now, an important part of the research in photocatalytic water splitting over the last four decades was concentrated on $\mathrm{d}^{0} \mathrm{Ti}^{4+}$ oxides like $\mathrm{TiO}_{2}$ or $\mathrm{SrTiO}_{3}^{[4,5,11}$ amongst other $\mathrm{d}^{0}$ or $\mathrm{d}^{10}$ oxides, mainly because of its unbeaten catalytic activity for (overall) water splitting, ${ }^{[4,12]}$ its low cost and long-term stability. The main drawback of titanium dioxide and many of the related oxides in general is their insensitivity for visible light (they often possess large band gaps and hence absorb only the UV portion of the solar spectrum) and the need to add cocatalysts based on scarce metals to enhance the activity for $\mathrm{H}_{2}$ evolution. ${ }^{[4]}$ In the PEC cell configuration an interesting example for a visible light-driven oxide photocatalyst is $\mathrm{Fe}_{2} \mathrm{O}_{3}$, since it is cheap, non-toxic, and consists of earth-abundant elements. The band gap of $2.0-2.2 \mathrm{eV}$ is in the proper range for water splitting, yet its conduction band is too low with respect to the $\mathrm{O}_{2}$ evolution potential.[13] In the PEC cell configuration, the band edges can be aligned with an external bias. However, the intrinsic properties of $\mathrm{Fe}_{2} \mathrm{O}_{3}$, e.g. the hole diffusion length, limit the performance of the material, although attempts like nanostructuring have been made to overcome them. ${ }^{[14]}$ Adding cocatalysts leads to an enhancement of the activity in PEC cells, again with the drawback that they often involve noble metals, while long-term stability issues can be addressed with protecting overlayers. ${ }^{[14,15]}$ In the search for suitable materials, another strategy is moving towards more complex systems, since it was believed that visible light absorption and good catalytic activity could be achieved by defect engineering and/or by cationic or anionic substitutions in already well known photocatalysts. ${ }^{[8,16]}$ In conclusion, although a lot of progress has been made, there is still vast room for improvement on the materials side for both photocatalytic and PEC cell applications.

\subsection{Perovskite-related Oxynitrides - An Approach to Design a Visible Light-driven Photocatalyst}

The perovskite structure is adopted by many ternary compounds with the general formula $\mathrm{ABX}_{3}$ (Fig. 2), where $\mathrm{A}$ and $\mathrm{B}$ are metal cations with coordination number 12 and 6, respectively, and $\mathrm{X}$ an element with strong electronegativity like $\mathrm{O}, \mathrm{N}$ or $\mathrm{S}$. Since the discovery of the perovskite $\mathrm{CaTiO}_{3}$ in $1840,{ }^{[17]}$ perovskites have been studied extensively and have shown a large variety of interesting material properties like colossal magnetoresistance, ferroelectricity ${ }^{[18]}$ and catalytic activity for water splitting. ${ }^{[12]}$ The reason for this broad range of properties comes from the large flexibility of the atomic arrangement, which provides the opportunity to accommodate cationic and anionic deficiencies and to incorporate a vast range of ions with different sizes and attributes. ${ }^{[19]}$ Depending on how large the deviation from the ideal size ratio between $\mathrm{A}, \mathrm{B}$ and $\mathrm{X}$ is, distortions from the ideal structure are observed. ${ }^{[20]}$ These distortions are not only of interest for fundamental studies, but they affect the physical properties of perovskite compounds, especially their electronic and magnetic properties. These dependencies have been studied extensively and are summarized in ref. [21]. The perovskite structure allows the electronic properties like the band gap to be tuned often within the same crystal structure by changing A, $\mathrm{B}$ and/or X. During these substitution and exchange reactions good crystallinity is obtained for many compositions and composition gradients, which is essential for photocatalytic applications, since an efficient electron and hole transport needs to be guaranteed.

In this brief overview we want to emphasize how extensively and how precisely the electronic properties of perovskites can be tuned. We concentrate our consider-

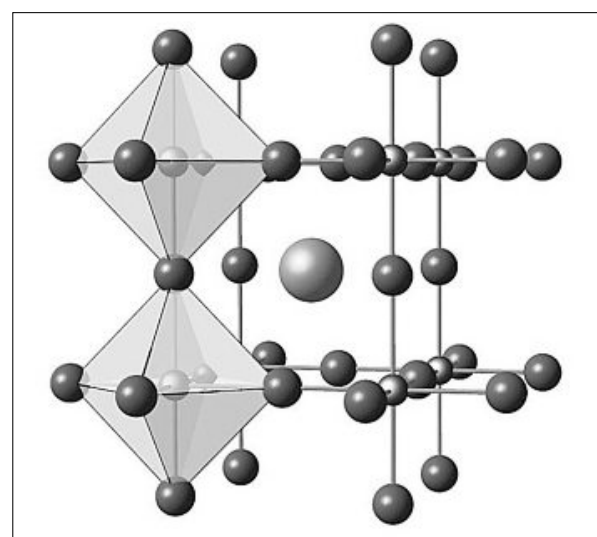

Fig. 2. Ideal perovskite structure: In the middle with $Z=12$ the A-site atom is situated. The smaller spheres at the edges indicate the position of the $X$-site anions, while in the middle of the octahedra the $B$-site atom $(Z=6)$ is located.

ations on compounds containing $\mathrm{d}^{0}$ metal B-site cations, since most of the catalytically active perovskites show this configuration, such as $\mathrm{SrTiO}_{3}$ or related structures like $\mathrm{SrNb}_{2} \mathrm{O}_{7}{ }^{[12]}$ An energy diagram of a typical $\mathrm{d}^{0}$ perovskite is shown in Fig. 1a with the example of $\mathrm{Ti}^{4+}$. The bottom of the valance band is mainly formed by nonbonding X 2 p orbitals (often O $2 p$ ), while the conduction band is constituted of $\pi^{*}$ antibonding states between the $t_{2 g}$ B-site metal d orbitals and some mixing of $\mathrm{X} 2 p$ orbitals. If the B-site cation is substituted, the width of the conduction band increases to the same extent as the electronegativity $\chi$ of the B-site cation increases. This results in a narrowing of the band gap with increasing electronegativity of the B-site cation. ${ }^{[22]}$ On the contrary, distortions of the $\mathrm{O}_{\mathrm{h}}$ symmetry around the B-site atom lead to an increase of the band gap, since any deviation from the ideal bond angle B-X-B $=180^{\circ}$ results in less orbital overlap and hence a narrower conduction band width. The direct influence of the A-site cation on the electronic structure close to the band gap is negligible, but via the A-site cation size distortions from the ideal symmetry around the B-site cation can be induced. This results in a band gap change. ${ }^{[22]}$ On the other hand, a much more direct way to modify the band gap consists in anionic substitution at the $\mathrm{X}$-site. Indeed, changing $\mathrm{X}$ has a direct influence on the position of the valence band edge. For example, the valence band is lifted up when oxygen is substituted with nitrogen, because nitrogen $\mathrm{N} 2 p$ orbitals are less electronegative than oxygen $\mathrm{O} 2 p$ orbitals. Additionally, it can be expected that the width of the conduction band increases since the B-N-B interaction is more covalent than the B-O-B bonding. [23]

These effects can be used to significantly improve the efficiency of photocatalytic water splitting, by tuning the band gap 
thus that the catalyst absorbs in the visible range instead of absorbing in the UV. ${ }^{[8]}$ Examining the highly catalytically active $\mathrm{Ti} \mathrm{d}^{0}$ metal oxides for the energetic position of the band gap edges with respect to the water-splitting half reactions, we find that in most $\mathrm{Ti} \mathrm{d}^{0}$-based catalysts the conduction band is well aligned with the $\mathrm{H}^{+} /$ $\mathrm{H}_{2}$ water splitting half reaction, but the valence band lies very low in comparison to the $\mathrm{O}^{2-} / \mathrm{O}_{2}$ half reaction, because of the very low lying $\mathrm{O} 2 p$ orbitals (Fig. 1a). Therefore an approach to design improved materials for water splitting is anionic substitution in (perovskite-related) oxides with more covalent and less electronegative anions than $\mathrm{O}^{2-}$ such as $\mathrm{N}^{3-}$. ${ }^{24]}$ Since the N $2 p$ orbitals show a slightly higher potential energy than the $\mathrm{O} 2 p$ orbitals, oxynitrides and nitrides exhibit a narrower band gap than the pure oxides which allows harvesting visible light due to the uplift of the valence band (see Fig. 1b). A similar approach has already been carried out successfully with several non-perovskite oxides like $\mathrm{ZnO}$, $\mathrm{Ta}_{2} \mathrm{O}_{5}{ }^{[8,25]}$ and some perovskite related oxides like $\mathrm{LaTi}_{2} \mathrm{O}_{7} \cdot{ }^{[26]}$

Another advantage of perovskites is the synthesis of stable A-site or B-site deficient perovskites. The vacancies in the deficient compounds can be filled with another species A' or B' allowing the formation of a well-defined composition gradient within the same crystal structure. The induced subtle changes in the conduction or valence band position throughout a catalyst particle has the potential to suppress the electron/hole recombination rate more efficiently than the hetero junction of a cocatalyst, because additional scattering on interfaces is avoided.

In this article the potential of perovskiterelated oxynitrides as efficient photocatalysts for water splitting is summarized, because they offer the possibility to absorb visible light and to be adapted to the manifold requirements by defect engineering and substitution. The presented studies are concentrated on $\mathrm{SrTiO}_{3}$ cosubstituted with $\mathrm{N}^{3-}$ and $\mathrm{Nb}^{5+}$ and on $\mathrm{LaTiO}_{2} \mathrm{~N}$ with A-site substitution with $\mathrm{Ca}^{2+}$.

\section{Experimental}

\subsection{Synthesis and Ammonolysis}

The synthesis of the material is performed mainly by a soft chemistry approach. The advantage of this approach is the possibility to synthesize high quality material at relatively low temperatures, i.e. $500{ }^{\circ} \mathrm{C} .{ }^{[27]}$ This strategy allows metastable materials to be synthesized which show a high level of deficiencies or high substitution rates which in many cases cannot be stabilized with a classic solid state reaction. Solid state reactions require much higher temperatures and the products are almost always obtained in the thermodynamically most stable phases. The details of the synthesis for the $\mathrm{SrTiO}_{3} / \mathrm{SrNbO}_{2} \mathrm{~N}$ system can be found in ref. [28], while the system $\mathrm{LaTiO}_{2} \mathrm{~N}$ including the A-site substitution of $\mathrm{Ca}$ has been summarized in ref. [29].

The introduction of nitrogen into the oxide lattice is accomplished by thermal ammonolysis. This is a reaction between a solid oxide precursor and ammonia in a constant gas flow at temperatures between $600^{\circ} \mathrm{C}$ and $1200{ }^{\circ} \mathrm{C}$. Ammonia dissociates at these temperatures and forms active nitriding species like $\mathrm{N}, \mathrm{NH}$ and $\mathrm{NH}_{2}$, as well as $\mathrm{H}_{2}$. Nitrogen is introduced into the lattice, whereas $\mathrm{H}_{2}$ forms $\mathrm{H}_{2} \mathrm{O}$ with lattice oxygen. ${ }^{[30]}$ The driving forces for the reaction towards the oxynitride are the formation of the thermodynamically stable $\mathrm{H}_{2} \mathrm{O}$ molecule and the overall entropy increase caused by the nitridation. The constant ammonia supply removes $\mathrm{H}_{2} \mathrm{O}$ and therefore hinders the back reaction. ${ }^{[30]}$ The ammonolysis conditions and their influence on the structure and properties of $\mathrm{SrTiO}_{3} /$ $\mathrm{SrNbO}_{2} \mathrm{~N}$ and $\mathrm{LaTiO}_{2} \mathrm{~N}$ have been described in detail. ${ }^{[24,28,29,31]}$

\subsection{Characterization}

An in-depth characterization of the material is necessary to distinguish structural effects (e.g. crystallite size, crystal quality and active surface area) from electronic effects on the photocatalytic activity introduced for example by substitution. X-ray diffraction (XRD) was used followed by Rietveld refinement, to determine the quality of the crystal structure and the crystallite size. Additional confirmation of crystallinity and particle/ crystallite size was obtained by TEM and/ or SEM. The cationic chemical composition was determined by X-ray fluorescence (XRF) or close to the surface by X-ray photoelectrons spectroscopy (XPS), while nitrogen content was measured by thermal gravimetry (TG). The surface area was determined by Brunauer-Emmett-Teller (BET) measurements. The band gap was determined by UV vis diffuse reflectance spectroscopy. The background signal at energies lower than the band gap was used as a fingerprint to assess the impurity level in the catalyst like oxygen vacancies or reduced $\mathrm{Ti}$ species. All details can be reviewed in refs $[28,29 \mathrm{~b}]$

\subsection{Photocatalytic Activity}

The photocatalytic activity is often assessed by studying half reactions, since spontaneous overall water splitting has not yet been achieved in many cases. ${ }^{[4]}$

The activity with respect to the $\mathrm{H}^{+} / \mathrm{H}_{2}$ reaction was determined using methanol as a sacrificial agent in a closed system.
The powders were dispersed in a solution consisting of $20 \mathrm{vol} \%$ methanol in water (standard solution). The irradiation source was a LOT-ORIEL 300W Xe lamp. The evolving gases were measured by gas chromatography. The set up and the measurement procedure are described in ref. [32].

For the $\mathrm{O}^{2-} / \mathrm{O}_{2}$ half reaction the activity was measured with $\mathrm{AgNO}_{3}$ as sacrificial agent. Photocatalytic water oxidation reactions were carried out in a closed system made of borosilicate glass. The catalyst powders were dispersed in a $10 \mathrm{mMAgNO}_{3}$ aqueous solution $(250 \mathrm{~mL})$ and were irradiated with a $150 \mathrm{~W}$ halogen lamp (Osram, HLX 64640) with a color temperature of $3550 \mathrm{~K}$ and continuous spectral emission peaking at $816 \mathrm{~nm}$. The $\mathrm{O}_{2}$ production was measured by gas chromatography. The detailed measurement protocol and set up can be found in ref. [29b].

\section{Results and Discussion}

\section{1 $\mathrm{SrTi}_{1-x} \mathrm{Nb}_{x} \mathrm{O}_{3-y} \mathrm{~N}_{y}$}

$\mathrm{SrTiO}_{3}$ is a known photocatalyst ${ }^{[4,12]}$ and attempts to shift its absorption to the range of visible light have been carried out before. Small amounts of $\mathrm{N}$ in the anionic sublattice have shown to effectively alter the band gap by introducing isolated $\mathrm{N} 2 p$ levels, ${ }^{[33]}$ but inevitably lead to detrimental defects such as O-deficiency or reduced B-site cations. To maintain the charge balance, it was chosen to substitute $\mathrm{Ti}^{4+}$ on the B-site by the slightly more electronegative $\mathrm{Nb}^{5+}$, which should contribute additionally to the reduction of the band gap, as explained in Section 1.2. A series of compounds $\mathrm{SrTi}_{1-\mathrm{Nb}} \mathrm{Nb}_{3-\mathrm{y}} \mathrm{N}_{\mathrm{y}}$ with $\mathrm{x}$ $=0,0.05,0.1,0.2,0.5,0.8,0.9^{y}$ and 0.95 were synthesized. As expected, the $\mathrm{N}$ incorporation followed closely the $\mathrm{Nb}$ content to maintain a neutral charge balance. Nitrogen incorporation proved to lower the band gap into the range of visible light. Consequently, the powders changed color from blue over green to red. The obtained band gap values varied from $3.31 \mathrm{eV}$ to $1.82 \mathrm{eV}$, respectively (Fig. 3). A nearly linear trend of the band gap decrease as a function of $\mathrm{Nb}$ content was observed from $\mathrm{x}=0$ to $\mathrm{x}=0.2$. This observation correlated very well with the model of intermixing $\mathrm{N}$ $2 p$ and $\mathrm{O} 2 p$ orbitals at the valence band edge, which predicted in first approximation a linear dependence of the band gap on the percentage of $\mathrm{N}$ substitution into the O-sites. However, the linear trend was interrupted for $\mathrm{y}=0.5$ and 0.8 by an even stronger decrease of the band gap due to the increased average electronegativity on the B-site caused by $\mathrm{Nb}$ substitution $(\chi=$ 1.6) on the Ti-site $(\chi=1.54)$. For $y=0.9$ and 0.95 we observed a return to the linear 
behavior. Since the crystal symmetry in these compounds was lowered from cubic $(\mathrm{Pmm})$ to tetragonal $(\mathrm{I} / \mathrm{mcm})$, the influence of changes in the bond angles on the electronic configuration have to be taken into account as well. Deviations from the ideal bond angle of $180^{\circ}$ are known to decrease the orbital overlap between the B $d$ and the $\mathrm{X} p$-orbitals resulting in a narrowing of the conduction band. This effect is counteracted by the conduction band width increase caused by the increasing electronegativity on the B-site. It can be concluded that these effects cancel out in the $\mathrm{SrTi}_{1-\mathrm{x}} \mathrm{Nb}_{\mathrm{x}} \mathrm{O}_{3-\mathrm{y}} \mathrm{N}_{\mathrm{y}}$ system for $\mathrm{x}=0.9$ and 0.95 and allowed thus the return to a linear dependence of the band gap on the $\mathrm{N}$ content. Extrapolating the linear trend to $\mathrm{x}=$ 1 , we would predict a band gap of $1.7 \mathrm{eV}$, which is slightly smaller than measured for $\mathrm{SrNbO}_{2} \mathrm{~N}$ with $1.9 \mathrm{eV} .^{[34]}$ The reason for such small variations can have its origin in different synthesis methods as well as minor deviations in the nitrogen content.

Five selected samples containing 5\%, $20 \%, 50 \%, 80 \%$ and $95 \%$ niobium were tested for their photocatalytic activity with respect to the $\mathrm{H}^{+} / \mathrm{H}_{2}$ half reaction. The overall values for $\mathrm{H}_{2}$ evolution are two order of magnitude lower than activities obtained from $\mathrm{Pt}$ promoted $\mathrm{TiO}_{2},{ }^{[35]}$ but higher than some values obtained for $\mathrm{SrTiO}_{3}$ with cocatalyst. ${ }^{[12]}$ However, since $\mathrm{SrTiO}_{3}$ does not show any $\mathrm{H}_{2}$ evolution without cocatalyst, the fact that some activity was found can be considered as a step in the right direction.

Fig. 4 shows that the hydrogen production rate as a function of $\% \mathrm{Nb}$ to $\mathrm{Ti}$ substitution follows a kind of volcano trend, centered at an optimum $\mathrm{Nb}$ substitution of $50 \%$. This trend can be partly attributed to the surface area which follows a similar trend. However, the hydrogen production rates normalized with respect to the surface area, listed in Table 1, still show the volcano trend. Thus, we estimate that the band gap value is important. Indeed, narrowing the band gap leads to a shift of the semiconductor absorption towards the visible, i.e. absorption of a larger part of the lamp emission spectrum, with a consequent increase of the hydrogen production rate. The highest rate is reached with $50 \%$ $\mathrm{Nb}$ substitution which exhibits a band gap of $2.01 \mathrm{eV}$. This is very close to the value of $\sim 2.1 \mathrm{eV}$, which is believed to be the best for photocatalytic water splitting activity. ${ }^{[9]}$ Increasing the $\mathrm{Nb}$ content leads to a further narrowing of the band gap which provokes a drop of the hydrogen production rate, very likely because of the now too narrow band gap, i.e. the photoexited electron-hole pairs have not enough energy to promote the electron transfer to the electron acceptor $\left(\mathrm{H}^{+}\right)$and donor $\left(\mathrm{H}_{2} \mathrm{O}\right)$ species.

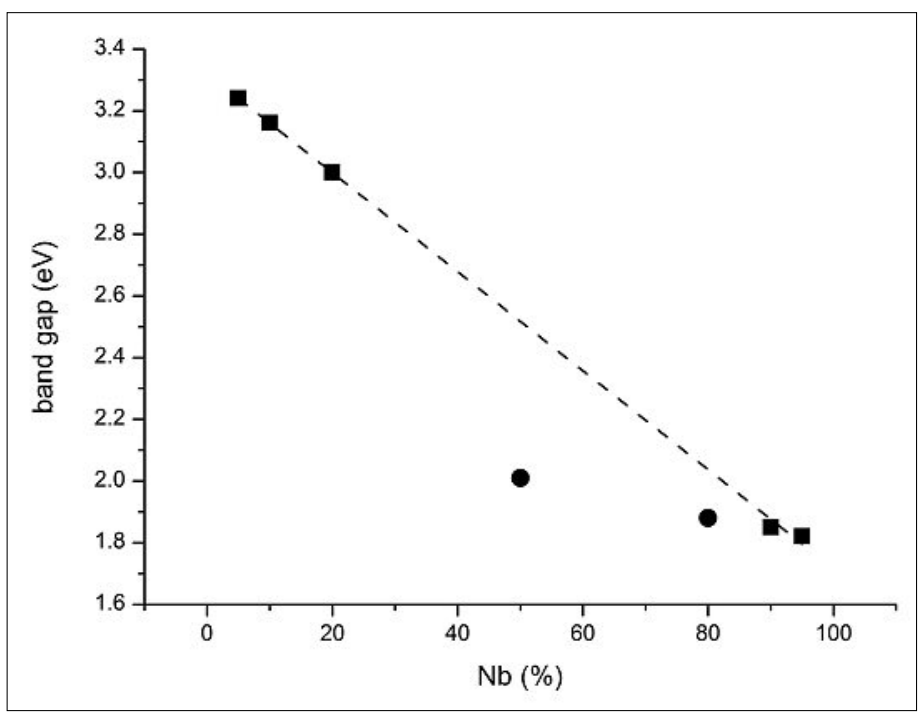

Fig. 3. The band gap of $\mathrm{SrTi}_{1-x} \mathrm{Nb}_{x} \mathrm{O}_{3-y} \mathrm{~N}_{y}$ as a function of the $\mathrm{Nb}$ content is displayed. The dashed lines denotes a linear fit through all data points apart from $\mathrm{Nb}$ $=50 \%$ and $80 \%$.

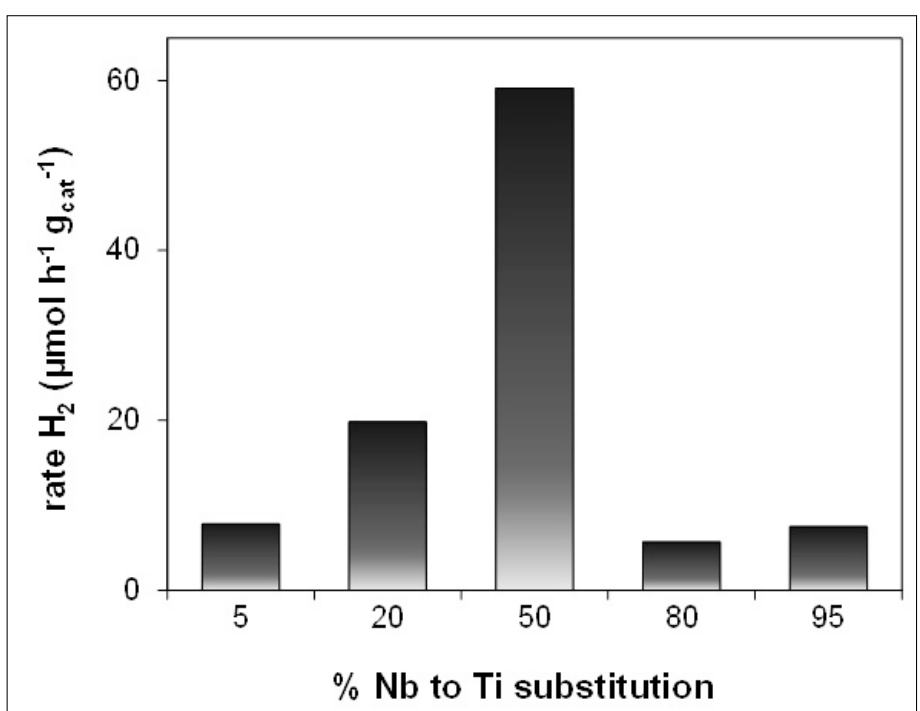

Fig. 4. Photocatalytic $\mathrm{H}_{2}$ production rate as a function of $\% \mathrm{Nb}$ to $\mathrm{Ti}$ substitution in $\mathrm{SrTi}_{1-\mathrm{x}} \mathrm{Nb}_{\mathrm{x}} \mathrm{O}_{3-\mathrm{y}} \mathrm{N}_{\mathrm{y}}$

The oxygen evolution rate of $\mathrm{SrTi}_{1-\mathrm{x}}$ $\mathrm{Nb}_{\mathrm{x}} \mathrm{O}_{3-\mathrm{y}} \mathrm{N}_{\mathrm{y}}$ was tested, but under the adopted measurement conditions the material turned out to be unstable, since $\mathrm{N}_{2}$ evolution was detected. The same behavior was found for the use of $\mathrm{SrTi}_{1-x} \mathrm{Nb}_{x} \mathrm{O}_{3-\mathrm{y}} \mathrm{N}_{\mathrm{y}}$ in PEC cells as photoanode. Since $\mathrm{SrTiO}_{3}$ is chemically stable under the adopted measurement conditions and oxynitrides in general as well, ${ }^{[8]}$ the high $\mathrm{Nb}$ content might be held responsible for the high reactivity of the compound, since $\mathrm{Nb}$ is easier reducible than Ti. Hence it can be concluded that the band gap shift into the visible can be achieved by anionic substitution with an optimum band gap for photocatalytic activities at around $2.1 \mathrm{eV}$, but that the overall stability of the compound under measurement conditions does not allow for long term applications.

\section{2 $\mathrm{LaTiO}_{2} \mathrm{~N}$}

In this system the $\mathrm{N}^{3-}$ in the anionic sublattice of the cubic perovskite structure is stabilized by substituting the A site cation of $\mathrm{SrTiO}_{3}$ by the three-valent cation $\mathrm{La}^{3+}$. The resulting compound is $\mathrm{LaTiO}_{2} \mathrm{~N}$ with a band gap of $\pm 0.05 \mathrm{eV}$ around the

Table 1. Surface area, band gap and $\mathrm{H}_{2}$ evolution of $\mathrm{SrTi}_{1-\mathrm{x}} \mathrm{Nb}_{x} \mathrm{O}_{2-y} \mathrm{~N}_{y}$

\begin{tabular}{|c|c|c|c|c|}
\hline $\begin{array}{c}\text { Cationic } \\
\text { composition }\end{array}$ & $\begin{array}{c}\text { Surface area } \\
{\left[\mathrm{m}^{2} \mathrm{~g}^{-1}\right]}\end{array}$ & $\begin{array}{c}\text { Band gap } \mathrm{E}_{\mathrm{g}} \\
{[\mathrm{eV}]}\end{array}$ & $\begin{array}{c}\mathrm{H}_{2} \\
\text { evolution rate } \\
{\left[\mu \mathrm{mol} \mathrm{h}{ }^{-1} \mathrm{~g}^{-1}\right]}\end{array}$ & $\begin{array}{c}\text { Normalized } \mathrm{H}_{2} \\
\text { evolution rate } \\
{\left[\mu \mathrm{mol} \mathrm{h}^{-1} \mathrm{~m}^{-2}\right]}\end{array}$ \\
\hline $\mathrm{SrTi}_{0.95} \mathrm{Nb}_{0.05}$ & 9.92 & 3.24 & 7.8 & 0.78 \\
\hline $\mathrm{SrTi}_{0.80} \mathrm{Nb}_{0.20}$ & 26.39 & 3.00 & 19.8 & 0.75 \\
\hline $\mathrm{SrTi}_{0.50} \mathrm{Nb}_{0.50}$ & 38.88 & 2.01 & 59.1 & 1.52 \\
\hline $\mathrm{SrTi}_{0.20} \mathrm{Nb}_{0.80}$ & 15.97 & 1.88 & 5.7 & 0.36 \\
\hline $\mathrm{SrTi}_{0.05} \mathrm{Nb}_{0.95}$ & 6.56 & 1.82 & 7.5 & 1.14 \\
\hline
\end{tabular}


optimum value of $2.1 \mathrm{eV}$ as a function of the ammonolysis time. This approach has the advantage that B-site substitution of $\mathrm{Ti}$ for $\mathrm{Nb}$ is avoided. Therefore the resulting system is less complex and easier to optimize. The details of synthesis and characterization are summarized in ref. [29a]. In contrast to the $\mathrm{SrTi}_{1-\mathrm{x}} \mathrm{Nb}_{\mathrm{x}} \mathrm{O}_{3-\mathrm{y}} \mathrm{N}_{\mathrm{y}}$ system $\mathrm{LaTiO}_{2} \mathrm{~N}$ used in this study does not show any $\mathrm{H}_{2}$ evolution at all with methanol as a sacrificial agent. However, it proved to act as a very effective photocatalyst for the $\mathrm{O}^{2-} / \mathrm{O}_{2}$ half reaction with $23 \mu \mathrm{mol} / \mathrm{h}$ in the presence of the sacrificial electron acceptor $\mathrm{Ag}^{+}$.

This promotes the material as an ideal candidate for a PEC photoanode, since it absorbs in the visible and there is a priori no band gap offset which needs to be corrected by applying a bias. Indeed an exceptional performance was reported using this material as a photoanode. ${ }^{[15]}$ Moreover, the performance could be improved by a factor of two to three by adding $\operatorname{In}_{2} \mathrm{O}_{3}$ as a cocatalyst. The main reason for its effectiveness was believed to lie either in a better electron hole separation due to the respective valence and conduction band positions of the cocatalyst in comparison to $\mathrm{LaTiO}_{2} \mathrm{~N}$ or due to the better charge extraction because of surface polarization. Moreover, the $\mathrm{In}_{2} \mathrm{O}_{3}$ could act as protection layer for LaTiO ${ }_{2} \mathrm{~N}$ against the reduction of $\mathrm{Ti}^{4+}$ to $\mathrm{Ti}^{3+}$ and to prevent outgassing of $\mathrm{N}_{2}$.

\section{$3.3(\mathrm{La}, \mathrm{Ca}) \mathrm{TiO}_{2} \mathrm{~N}$}

Following up on the idea to enhance the electron hole separation and extraction by changing valence band and conduction band positions at the surface of the catalyst particle and/or to shield the $\mathrm{Ti}^{4+}$ against reduction by a protecting layer, we studied the effect of a composition gradient in a particle. A gradient within the same crystal structure has the potential to be more effec-

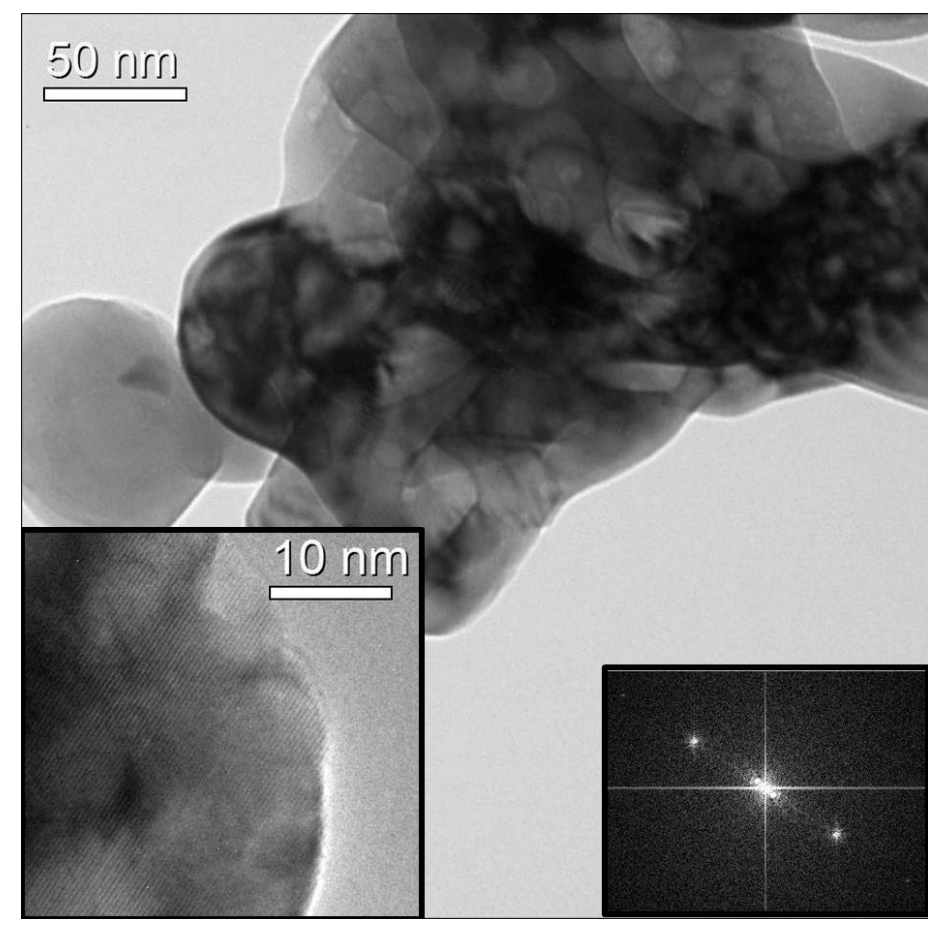

Fig. 5. TEM image of LaTiO $\mathrm{N}$ backfilled with $5 \% \mathrm{Ca}$. The inset on the left shows a high resolution (HR) micrograph of the particle edge displaying lattice fringes. The high degree of crystallinity of the entire particle including the near surface regions is confirmed by the right inset showing lattices planes in the Fast Fourier Transform of the HREM micrograph.

tive than adding a cocatalyst, since there is no additional interface which might lead to scattering and hence recombination. In the perovskite structure composition gradients can be achieved by preparing an A-site or B-site deficient oxide and impregnating this material prior to the nitridation reaction with an alternative cation. Here an A-site deficient material ( $\mathrm{La}^{3+}$ deficient) was synthesized and an alternative A-site cation (here $\mathrm{Ca}^{2+}$ ) was backfilled into the empty A-sites. $\mathrm{Ca}$ is a good candidate since $\mathrm{CaTiO}_{3}$ has a large band gap of 3.4 $\mathrm{eV}$, which is slightly larger than $\operatorname{In}_{2} \mathrm{O}_{3}$ with $3 \mathrm{eV}$ and $\mathrm{Ca}^{2+}$ has only one available oxidation state. Hence it could serve either to create band gap offsets or to protect the $\mathrm{Ti}^{4+}$ against reduction. Since backfilling is a diffusion process, more $\mathrm{Ca}^{2+}$ was expected close to the surface than in the inside of the

Table 2. Surface area, band gap, crystallite size and $\mathrm{O}_{2}$ evolution rate of $\mathrm{La}_{1-\mathrm{x}} \mathrm{Ca}_{\mathrm{x}} \mathrm{TiO}_{2+y} \mathrm{~N}_{1-y}$

\begin{tabular}{|l|c|c|c|c|}
\hline Sample & $\begin{array}{c}\text { Surface area } \\
{\left[\mathrm{m}^{2} / \mathrm{g}\right]}\end{array}$ & $\begin{array}{c}\text { Band gap } \\
{[\mathrm{eV}]}\end{array}$ & $\begin{array}{c}\text { Crystallite } \\
\text { size from } \\
\text { XRD [nm] }\end{array}$ & $\begin{array}{c}\mathrm{O}_{2} \text { evolution } \\
\text { activity } \\
{[\text { umol/h] }}\end{array}$ \\
\hline $\mathrm{LaTiO}_{2} \mathrm{~N}$ & 12.2 & 2.1 & 39 & 22 \\
\hline Backfilled & & & & 40 \\
\hline $\mathrm{La}_{0.95} \mathrm{Ti}(\mathrm{ON})_{3-\delta}: 5 \% \mathrm{Ca}$ & 12.8 & 2.1 & 46 & 30 \\
\hline $\mathrm{La}_{0.90} \mathrm{Ti}(\mathrm{ON})_{3-\delta}: 10 \% \mathrm{Ca}$ & 9 & 2.1 & 51 & 27 \\
\hline $\mathrm{La}_{0.80} \mathrm{Ti}(\mathrm{ON})_{3-\delta}: 20 \% \mathrm{Ca}$ & 9.7 & 2.1 & 59 & 31 \\
\hline $\mathrm{La}_{0.70} \mathrm{Ti}(\mathrm{ON})_{3-\delta}: 30 \% \mathrm{Ca}$ & 8.8 & 2.1 & $106 \& 40$ & 16 \\
\hline $\mathrm{Substituted}^{\mathrm{L}}$ & & & & 13 \\
\hline $\mathrm{La}_{0.95} \mathrm{Ca}_{0.05} \mathrm{TiO}_{2.05} \mathrm{~N}_{0.95}$ & 13.5 & 2.1 & 41 & 15 \\
\hline $\mathrm{La}_{0.90} \mathrm{Ca}_{0.10} \mathrm{TiO}_{2.10} \mathrm{~N}_{0.90}$ & 13.5 & 2 & 42 & 27 \\
\hline $\mathrm{La}_{0.80} \mathrm{Ca}_{0.20} \mathrm{TiO}_{2.20} \mathrm{~N}_{0.80}$ & 8.4 & 2.1 & 57 & 75 \\
\hline $\mathrm{La}_{0.70} \mathrm{Ca}_{0.30} \mathrm{TiO}_{2.30} \mathrm{~N}_{0.7} \mathrm{O}$ & 8.6 & 2 & & \\
\hline
\end{tabular}

$\mathrm{LaTiO}_{2} \mathrm{~N}$ particle. The bulk-surface composition gradient between $\mathrm{LaTiO}_{2} \mathrm{~N}$ and $\mathrm{CaTiO}_{3}$ or some intermediate compound was confirmed by XPS, while transmission electron microscopy (TEM) confirmed the high crystallinity even close to the particle surface (see Fig. 5). For comparison $\mathrm{La}_{1-\mathrm{x}} \mathrm{Ca}_{\mathrm{x}} \mathrm{TiO}_{2+\mathrm{y}} \mathrm{N}_{1-\mathrm{y}}$ was conventionally synthesized by substitution leading to a homogeneous distribution of the $\mathrm{Ca}^{2+}$ in the $\mathrm{LaTiO}_{2} \mathrm{~N}$. Both series were fabricated with $5 \%, 10 \%, 20 \%$ and $30 \%$ Ca content, respectively. The synthesis procedures and the characterization were summarized in ref. [29b]. The main results concerning the photocatalytic activity with respect to the $\mathrm{O}^{2-} / \mathrm{O}_{2}$ half reaction are displayed in Table 2 .

Indeed Ca-backfilled samples exhibit globally higher catalytic activity. Moreover, it is important to note that all samples show a band gap around $2.1 \mathrm{eV}$, although an increasing $\mathrm{Ca}^{2+}$ and therefore possibly $\mathrm{CaTiO}_{3}$ content could be expected to give rise to a band gap shift. ${ }^{[36]} \mathrm{A}$ possible interpretation is that the $\mathrm{N}$ content is largely unaffected by the $\mathrm{Ca}^{2+}$ incorporation which would mean that $\mathrm{O}$ vacancies are generated in the material, if the charge balance is respected. However, some of the structural parameters like crystallite size and surface area varied as well. Therefore it was difficult to unambiguously conclude on the main cause for the enhanced activity of backfilled samples compared to (Casubstituted) $\mathrm{LaTiO}_{2} \mathrm{~N}$, since a combination of electronic effects like band gap offsets between $\mathrm{CaTiO}_{3}$ and $\mathrm{LaTiO}_{2} \mathrm{~N}$ or the passivation effect of $\mathrm{CaTiO}_{3}$ and structural variations like crystallinity and surface area might be equally responsible for the improved catalytic activity of backfilled 
samples compared to (Ca-substituted) $\mathrm{LaTiO}_{2} \mathrm{~N}$.

\section{Conclusions}

In this review we illustrate that the perovskite system is very flexible to tune the properties of a photocatalyst. The shift of the band gap from UV to visible light absorption by anionic substitution on the $\mathrm{SrTi}_{1-x} \mathrm{Nb}_{\mathrm{x}} \mathrm{O}_{3-\mathrm{y}} \mathrm{N}_{\mathrm{y}}$ system was demonstrated. A closely related compound, $\mathrm{LaTiO}_{2} \mathrm{~N}$, is a very active visible light absorbing photocatalyst for the $\mathrm{O}^{2-} / \mathrm{O}_{2}$ reaction, which acted as a highly efficient photoanode in a PEC cell. Moreover, it showed increased efficiencies when A-site substitution gradients were generated by Ca backfilling. In future studies we will explore the effect of the Ca-substitution gradients on the PEC efficiency of $\mathrm{LaTiO}_{2} \mathrm{~N}$. On the material side we would like to isolate the band gap shift produced by $\mathrm{N}$ incorporation from the A- or B-site substitution effects. This could be achieved by anionic co-substitution of for example $\mathrm{F}$ and $\mathrm{N}$ into a perovskite oxide.

\section{Acknowledgement}

The authors would like to thank E. Selli, University of Milano, for carrying out the photocatalytic hydrogen producton measurements and $\mathrm{O}$. Brunko for his support in drawing the figures. This research has been funded by the European Commission (Project NanoPEC, Contract number 227179).

Received: December 21, 2012
[1] A. Fujishima, K. Honda, Nature 1972, 238, 37.

[2] Y. Tachibana, L. Vayssieres, J. R. Durrant, Nat. Photon 2012, 6, 511.

[3] G. L. Chiarello, E. Selli, Recent Patents on Engineering 2010, 4, 155

[4] A. Kudo, Pure Appl. Chem. 2007, 79, 1917.

[5] M. Grätzel, Nature 2001, 414, 338.

[6] A. Paracchino, V. Laporte, K. Sivula, M. Grätzel, E. Thimsen, Nature Mater. 2011, 10, 456.

[7] D. E. Scaife, Solar Energy 1980, 25, 41.

[8] K. Maeda, K. Domen, J. Phys. Chem. C 2007, $111,7851$.

[9] S. Fiechter, Adv. Appl. Ceram. 2012, 111, 39.

[10] A. J. Nozik, R. Memming, J. Phys. Chem. 1996, 100,13061

[11] A. L. Linsebigler, G. Lu, J. T. Yates, Chem. Rev. $\mathbf{1 9 9 5}, 95,735$.

[12] K. Domen, S. Naito, M. Soma, T. Onishi, K. Tamaru, J. Chem. Soc., Chem. Comm. 1980, 543.

[13] F. Le Formal, M. Grätzel, K. Sivula, Adv. Funct. Mater. 2010, 20, 1099.

[14] A. Valdes, J. Brillet, M. Grätzel, H. Gudmundsdottir, H. A. Hansen, H. Jonsson, P. Klupfel, G.-J. Kroes, F. Le Formal, I. C. Man, R. S. Martins, J. K. Norskov, J. Rossmeisl, K. Sivula, A. Vojvodic, M. Zach, Phys. Chem. Chem. Phys. 2012, 14, 49.

[15] C. M. Leroy, A. E. Maegli, K. Sivula, T Hisatomi, N. Xanthopoulos, E. H. Otal, S. Yoon, A. Weidenkaff, R. Sanjines, M. Grätzel, Chem. Commun. 2012, 48, 820 .

[16] a) T. Takata, K. Domen, J. Phys. Chem. C 2009, 113, 19386; b) M. K. Nowotny, L. R. Sheppard, T. Bak, J. Nowotny, J. Phys. Chem. C 2008, $112,5275$.

[17] G. Rose, J. Prakt. Chemie 1840, 19, 459.

[18] A. Weidenkaff, Adv. Eng. Mater. 2004, 6, 709.

[19] H. Zhang, N. Li, K. Li, D. Xue, Acta Cryst. Section B 2007, 63, 812.

[20] P. Woodward, Acta Cryst. Section B 1997, 53, 32.

[21] a) T. Mizokawa, A. Fujimori, Phys. Rev. B 1996, 54, 5368; b) N. Hamada, H. Sawada, I. Solovyev, K. Terakura, Physica B: Cond. Matter 1997, 237-238, 11.

[22] H. W. Eng, P. W. Barnes, B. M. Auer, P. M. Woodward, J. Solid State Chem. 2003, 175, 94.
[23] R. Aguiar, D. Logvinovich, A. Weidenkaff, A. Rachel, A. Reller, S. G. Ebbinghaus, Dyes and Pigments 2008, 76, 70 .

[24] R. Marchand, Comp. Rend. Acad. Sci IIC 1999, 2,669 .

[25] M. Hara, G. Hitoki, T. Takata, J. N. Kondo, H. Kobayashi, K. Domen, Catal. Today 2003, 78 , 555.

[26] R. Aguiar, A. Kalytta, A. Reller, A. Weidenkaff, S. G. Ebbinghaus, J. Mater. Chem. 2008, 18 , 4260 .

[27] M. Kakihana, T. Okubo, M. Arima, Y. Nakamura, M. Yashima, M. Yoshimura, J. SolGel Sci. Technol. 1998, 12, 95.

[28] A. Maegli, S. Yoon, E. Otal, L. Karvonen, P. Mandaliev, A. Weidenkaff, J. Solid State Chem. 2011, 184, 929.

[29] a) A. E. Maegli, E. H. Otal, T. Hisatomi, S. Yoon, C. M. Leroy, N. Schäuble, Y. Lu, M. Grätzel, A. Weidenkaff, Ener. Proc. 2012, 22, 61; b) A. E. Maegli, T. Hisatomi, E. Otal, S. Yoon, S. Pokrant, M. Grätzel, A. Weidenkaff, $J$. Mater. Chem. 2012, 22, 17906.

[30] S. G. Ebbinghaus, H.-P. Abicht, R. Dronskowski, T. Müller, A. Reller, A. Weidenkaff, Prog. Solid State Chem. 2009, 37, 173.

[31] a) D. Logvinovich, S. G. Ebbinghaus, A. Reller, I. Marozau, D. Ferri, A. Weidenkaff, Z. Anorg. Allg. Chem. 2010, 636, 905; b) A. Fuertes, Dalton Trans. 2010, 39, 5942; c) A. Fuertes, J. Mater. Chem. 2012, 22, 3293; d) R. Marchand, Y. Laurent, J. Guyader, P. L'Haridon, P. Verdier, J. Eur. Ceram. Soc. 1991, 8, 197.

[32] G. L. Chiarello, E. Selli, L. Forni, Appl. Catal. B: Environ. 1980, 84, 332

[33] C. M. Liu, Z. L. Yuan, Y. F. Ju, X. Xiang, X. T Zu, W. L. Zhou, Can. J. Phys. 2008, 86, 145

[34] Y.-I. Kim, P. M. Woodward, K. Z. Baba-Kishi, C. W. Tai, Chem. Mater. 2004, 16, 1267.

[35] M. Ni, M. K. H. Leung, D. Y. C. Leung, K. Sumathy, Renew. Sust. Ener. Rev. 2007, 11, 401.

[36] D. Logvinovich, A. Börger, M. Döbeli, S. G. Ebbinghaus, A. Reller, A. Weidenkaff, Prog. Solid State Chem. 2007, 35, 281. 